\title{
Evolutionary relationships of Ctenomys (Rodentia: Octodontidae) from Argentina, based on penis morphology*
}

\author{
Javier BALBONTIN, Santiago REIG** and Sacramento MORENO
}

Balbontin J., Reig S. and Moreno S. 1996. Evolutionary relationships of Ctenomys (Rodentia: Octodontidae) from Argentina, based on penis morphology. Acta Theriologica 41: $237-253$.

Analyses of qualitative and quantitative variation in bacula and soft parts of the glans penis of 13 species of Ctenomys Blainville, 1926 from Argentina were used to suggest systematic and evolutionary relationships. The 13 species can be divided into spike-bearing (C. australis, C. azarae, C. porteousi, C. rionegrensis, and C. talarum) and spiny bulb-bearing species $(C$. dorbignyi, C. pearsoni, C. perrensi, C. roigi, Ctenomys sp. from Curuzú Laurel, Ctenomys sp. from M. F. Mantilla, and Ctenomys sp. from San Roque). Ctenomys yolandae is unique because it shows both spikes and spiny bulbs. In addition to spikes and spiny bulbs, some populations of $C$. pearsoni, C. talarum, and C. yolandae had a new structure, an inner sac of the intromittent sac. The most frequent pattern of occurrence of spikes or spiny bulbs was 1-1 (one at each side of the urethra), an ancestral character state in caviomorphs. Variation in bacular dimensions was limited and differences among species were small, with the exception of $C$. pearsoni. This species showed a significantly short baculum with a wide base. Sperm and penial morphology suggests that $C$. talarum is the most plesiomorphic and C. yolandae the most derived species of this group. The pattern of geographic variation among these 13 species rejects the hypothesis of penis morphology contributing to reproductive isolation. Ctenomys pearsoni is the only species with some evidence of reproductive isolation resulting from penis morphology.

Estación Biológica de Doñana, CSIC, Apdo. 1056, Sevilla 41080, Spain (JB, SM); Museo Nacional de Ciencias Naturales, CSIC, José Gutierrez Abascal 2, Madrid 28006, Spain. Mustela@Pinar1.Csic.es (SR)

Key words: Ctenomys, Rodentia, penial morphology, reproductive isolation, evolution, speciation

\section{Introduction}

Within caviomorph rodents (New World hystricognaths), the genus Ctenomys Blainville, 1926 tuco-tucos, includes a large number of species that exploit a wide variety of fossorial habitats ranging from sea level to $4000 \mathrm{~m}$. Species of Ctenomys

\footnotetext{
*This paper is dedicated to the memory of the distinguished mammalogist Professor O. A. Reig, initiator and partial supervisor of this project, for his courageous enthusiasm and sacrifices devoted to Ctenomys research in the late stage of his life and his erudite thoughts about the amazing problems involved in the evolutionary biology of this and other groups of mammals.

**To whom all correspondence should be addressed.
} 
occur from southern Peru, Bolivia, and southern Brazil southward to Patagonia in Chile and Argentina. Systematic studies of this genus document an extraordinary rate of speciation, similar to other subterranean rodents (Nevo 1982). Diversification began in the Middle Pleistocene, producing a large number of taxa; currently more than 56 living species and 13 subspecies have been described (Reig et al. 1990). Although a more conservative estimate of 39 species has been proposed (Woods 1993), new species are regularly being added to the list (Kelt and Gallardo 1994). One sign of the high variability in this genus is its karyotypic heterogeneity, with diploid numbers ranging from 10 to 70 (Reig et al. 1990). The high rate of diversification in Ctenomys, its variability in chromosome numbers, patterns of heterochromatin banding, presence of highly repetitive DNA sequences, and other cytogenetic traits (Reig et al. 1992) suggests that chromosomal evolution has accelerated the rate of speciation in the genus (Ortells 1990, Reig et al. 1990, Ortells and Barrantes 1994, Ortells 1995).

Morphological variation within the genus, evidenced by the large range in body size (from 100 to $1100 \mathrm{~g}$ in weight), has not been thoroughly studied, and the extent to which it parallels karyotypic variability remains largely unknown. A study of bacular and penial variation may provide information about the morphological variability of the genus, thus possible systematics and phylogenic relationships within the genus, as exemplified in other rodents (Lidicker 1968, Williams 1982). Furthermore, any evidence of penis variability may be relevant to appreciating possible mechanisms of reproductive isolation between closely related species (Patterson and Thaeler 1982, Edwards 1993). The influence of penial differentiation in the speciation processes of fossorial rodents is supported with Spalax ehrenbergi (Simson et al. 1993).

The glans penis of hystricognath rodents shows a characteristic intromittent sac (sacculus urethralis) which displays internal structures that have been described in most caviomorphs (Pocock 1922, Spotorno 1979, Contreras et al. 1993). Detailed studies of penial variation in Ctenomys have been made in only two Uruguayan species (Altuna and Lessa 1985). Another study (Lessa and Cook 1989) analyzed the presence of spikes and spiny bulbs inside the intromittent sac of 14 species of Ctenomys. That investigation focused on the independent variability of penial characters relative to overall morphology changes (eg body size), thus corroborating the evolutionary significance of this reproductive organ.

This contribution describes morphological variation of the glans penis among species of Ctenomys distributed through central and northwest Argentina. These data supplement previous work on allozyme variation (Ortells and Barrantes 1994), karyotypes (Ortells 1995), and sperm morphology (Vitullo et al. 1988, Ortells 1990, Vitullo and Cook 1991), thus collectively contributing to a better understanding of the systematics of Ctenomys. In particular, the study of the group of species from Corrientes will increase the data available to elucidate the possible role of chromosomal rearrangements in the speciation process (Ortells and Barrantes 1994, Ortells 1995). 


\section{Materials and methods}

A total of 150 specimens were used in this study. Taxa included C. australis, C. azarae, C. dorbignyi, C. pearsoni, C. perrensi, C. porteousi, C. rionegrensis, C. roigi, C. talarum, C. yolandae, and Ctenomys spp. (three undescribed species from Curuzú Laurel, M. F. Mantilla, and San Roque). The sample of $C$. talarum includes populations within the range of two subspecies (Contreras and Reig 1965). Populations from Magdalena and Saladillo belong to C. t. talarum and populations from Camet Norte and Necochea belong to C. $t$. recesus. All specimens were collected from 22 populations in Argentina (Fig. 1), collecting localities included the provinces of Buenos Aires (Bonifacio, Camet Norte, Magdalena, Necochea, Saladillo), Corrientes (Costa Mansión near Empedrado, Curuzú Laurel near San Miguel, Goya, Estación M. F. Mantilla near Pedro R. Fernandez, Mbaragüí, Saladas, San Roque, Sarandicito near Esquina, Yataití-Calle), Entre Ríos (Ibicuy, Medanos, Paraná), La Pampa (El Guanaco near Santa Rosa, Saladillo, Santa Rosa), and Santa Fe (Las Palmas). Species and sample size for each locality are listed in Table 1 . Voucher specimens were deposited in the Museo Nacional de Ciencias Naturales (Madrid, Spain) and GIBE (Grupo de Investigación en Biología Evolutiva, Universidad de Buenos Aires, Buenos Aires, Argentina).

Phalli were removed from fresh specimens after capture and fixed in $10 \%$ formalin. For the anatomical study, glans penes were dissected ventrally at the level of the intromittent sac. Morphological examination was performed with a Wild MB stereomicroscope and scale drawings of each specimen were made by using a camera lucida. On the scale drawings made through the stereomicroscope, maximum length and width at the base of spikes or of spiny bulbs was measured to the nearest $0.01 \mathrm{~mm}$ using digital calipers. To study the baculum, after morphological examination of the soft parts was completed, phalli were cleared using a \% KOH solution and stained with Alizarin Red (Lidicker 1968). Bacular bones were not removed from the glans penis. Measurements (see below) were performed directly on the stained bones.

Fig. 1. Geographic location of the 22 populations of Ctenomys studied. In localities where more than one population was sampled species names are followed by the initials of the populations, as they appear in Tables 1,2 and 3. Spike-bearing species are marked with an "s" while "b" represents species with spiny bulbs.

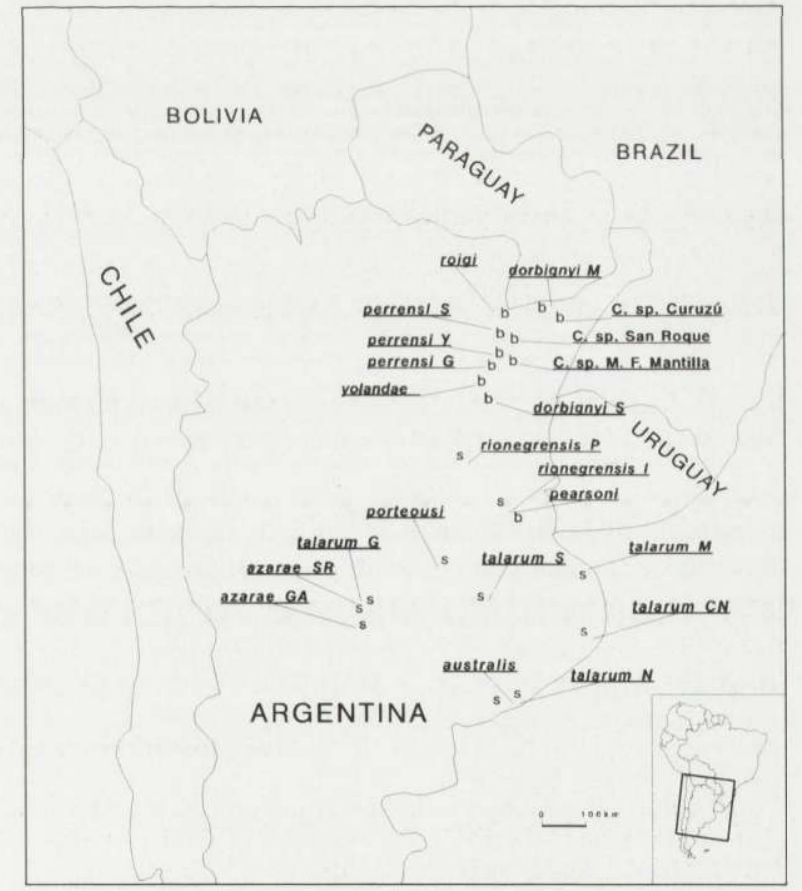


Table 1. Sample size $(n)$ and pattern of occurrence of spikes, inner sac and spiny bulbs found inside the intromittent sac of 22 populations of Ctenomys from Argentina. A "1-0" pattern indicates presence of one penial structure (spike, inner sac, spiny bulb) on the right and none on the left, and so on (Spotorno 1979). To simplify the table, the 0-0 pattern of inner sac occurrence is omitted. ${ }^{\mathrm{a}}$ Some specimens showed spikes and spiny bulbs at the same time.

\begin{tabular}{|c|c|c|c|c|c|c|c|c|c|c|c|c|c|c|c|c|}
\hline \multirow{2}{*}{ Species } & \multirow{2}{*}{ Locality } & \multirow{2}{*}{$n$} & \multicolumn{9}{|c|}{ Spike } & \multicolumn{2}{|c|}{ Inner sac } & \multicolumn{3}{|c|}{ Spiny bulb } \\
\hline & & & $0-0$ & $0-1$ & $1-1$ & $1-2$ & $1-3$ & $2-0$ & $2-1$ & $2-2$ & $2-3$ & $1-0$ & $0-1$ & $0-0$ & $0-1$ & $1-1$ \\
\hline C. australis & Necochea & 7 & & 1 & 5 & & 1 & & & & & & & & & \\
\hline C. azarae & $\begin{array}{l}\text { General Acha } \\
\text { Santa Rosa }\end{array}$ & $\begin{array}{l}6 \\
1\end{array}$ & 1 & & $\begin{array}{l}5 \\
1\end{array}$ & & & & & & & & & & & \\
\hline C. porteousi & Bonifacio & 1 & & & 1 & & & & & & & & & & & \\
\hline C. rionegrensis & $\begin{array}{l}\text { Ibicuy } \\
\text { Paraná }\end{array}$ & $\begin{array}{l}9 \\
5\end{array}$ & $\begin{array}{l}4 \\
5\end{array}$ & & 4 & 1 & & & & & & & & & & \\
\hline C. talarum & $\begin{array}{l}\text { Camet Norte } \\
\text { El Guanaco } \\
\text { Magdalena } \\
\text { Necochea } \\
\text { Saladillo }\end{array}$ & $\begin{array}{r}10 \\
6 \\
9 \\
12 \\
9\end{array}$ & 1 & 1 & $\begin{array}{r}10 \\
3 \\
7 \\
6 \\
5\end{array}$ & & & & 1 & 1 & 1 & $\begin{array}{l}2 \\
1 \\
2\end{array}$ & 5 & & & \\
\hline C. dorbignyi & $\begin{array}{l}\text { Mbaragüí } \\
\text { Sarandicito }\end{array}$ & $\begin{array}{l}6 \\
6\end{array}$ & & & & & & & & & & & & 4 & 1 & $\begin{array}{l}1 \\
6\end{array}$ \\
\hline C. pearsoni & Medanos & $8^{\mathrm{a}}$ & & & 1 & & & & & & & 1 & 1 & 2 & 1 & 5 \\
\hline C. perrensi & $\begin{array}{l}\text { Goya } \\
\text { Saladas } \\
\text { Yataití }\end{array}$ & $\begin{array}{r}9 \\
16 \\
4\end{array}$ & & & & & & & & & & & & $\begin{array}{l}1 \\
3 \\
1\end{array}$ & 1 & $\begin{array}{r}8 \\
12 \\
3\end{array}$ \\
\hline C. roigi & Costa Mansión & 6 & & & & & & & & & & & & & & 6 \\
\hline C. yolandae & Las Palmas & $5^{\mathrm{a}}$ & & & 3 & & & 1 & & & & & 1 & 1 & & 3 \\
\hline $\begin{array}{l}\text { Ctenomys sp. } \\
\text { Ctenomys sp. } \\
\text { Ctenomys sp. }\end{array}$ & $\begin{array}{l}\text { Curuzú Laurel } \\
\text { M. F. Mantilla } \\
\text { San Roque }\end{array}$ & $\begin{array}{l}2 \\
8 \\
5\end{array}$ & & & & & & & & & & & & 1 & & $\begin{array}{l}2 \\
8 \\
4\end{array}$ \\
\hline
\end{tabular}

\section{Qualitative analysis}

The study of qualitative variation of phallic structures inside the intromittent sac included: (i) the occurrence of spikes or of spiny bulbs inside the intromittent sac, (ii) the number of these structures found, and (iii) their location at the left, right, or both sides of the intromittent sac. Documentation of patterns of spike or spiny bulb presence are referred to as $0-1$ if there was only a spike or a spiny bulb on the left side and nothing on the right, 1-1 if there was one spike or spiny bulb at each side, 2-1 when there were two spikes or spiny bulbs at the right side and one on the left, and so on (Spotorno 1979). Frequency of occurrence of these patterns was recorded for every population.

\section{Morphometric analysis}

Bacular measurements included maximum length (maximum distance from the base to the distal half of the bone), distal width (maximum width at the proximal half of the bone), proximal width (maximum width at the base of the bone), and height (on the sagittal plane, greatest dorsoventral 
distance across the base of the baculum). Head and body length was also recorded for allometric analysis of penial structures relative to body size.

Specimens were aged as immatures or adults by examination of skull and skeletal sutures. To avoid bias of size changes due to growth, only adult specimens were used for morphometric analysis of the bacula and penial structures. Complete absence or little development of penial structures inside the intromittent sac was another indication of immature individuals, which were also excluded from the morphometric analysis.

Analysis of variance was used to test significant differences in bacular dimensions among populations with sufficiently large sample sizes. Allometric relationships between size of the baculum and body size were made by fitting a linear regression model. With species having sufficiently larger sample sizes, estimation of overall morphometric differences among species was made by the generalized Mahalanobis' $\mathrm{D}^{2}$ distance on $\log$ transformed data of the four baculum variables. Mahalanobis' $\mathrm{D}^{2}$ is a multivariate measure of dissimilarity that maximizes between group variation relative to within group variation. A matrix of dissimilarity among species was constructed with these $\mathrm{D}^{2}$ values, and a UPGMA phenogram was built using the NTSYS program (Rohlf 1992). COPH and MXCOMP routines of NTSYS were used to test the goodness of fit of the cluster analysis to the original dissimilarity matrix. Statistical analysis were made with the BMDP package (Dixon 1992).

\section{Results}

\section{Variability of internal penial structures}

The glans penes examined from 22 populations of Ctenomys exhibited morphological structures similar to those described in other species of this genus (Altuna and Lessa 1985). One or more spikes, or spiny bulbs were found inside the intromittent sac, and only immature individuals exhibited an empty sac resulting in a $0-0$ pattern. Spikes were globular or flat shaped; spiny bulbs showed small (around $0.7 \mathrm{~mm}$ long) spikes at the base, as already described in C. pearsoni (Altuna and Lessa 1985). In addition to spikes and spiny bulbs, some populations of C. pearsoni, C. talarum and C. yolandae exhibited a different structure which has not been reported in other hystricognaths that have the intromittent sac. This structure, referred to as the "inner sac" consists of a folding of the inner wall of the intromittent sac. This folding emerges at the base of spikes and spiny bulbs and closes over one side of the urethra. Spikes or spiny bulbs are inserted inside the cavity formed by this structure (Fig. 2).

Based on whether spikes or spiny bulbs were the phallic structures present inside the intromittent sac, two groups of Ctenomys species arise among the 13 studied. One group of species bears spikes and includes C. australis, C. azarae, C. porteousi, C. rionegrensis, and C. talarum. The other group exhibits pairs of spiny bulbs as in C. dorbignyi, C. pearsoni, C. perrensi, C. roigi, and Ctenomys sp. from Curuzú Laurel, M. F. Mantilla, and San Roque. C. yolandae is unique because some individuals show both structures, spikes and spiny bulbs (Table 1).

The most common spike pattern was 1-1 in all species examined (Table 1). Exceptions to this general trend were two specimens of $C$. australis, having a 0-1 pattern, and the other a 1-3 pattern. One specimen of $C$. rionegrensis from the Ibicuy population had a $0-1$ pattern (Table 1). In C. talarum, some specimens 
showed an inner sac always with a 1-0 pattern; this species shows some interand intrapopulational variation in the pattern of spikes (Table 1).

The group of species showing spiny bulbs followed a consistent pattern of $1-1$, with the exception of one specimen of $C$. perrensi from Saladas (Table 1). In C. pearsoni, three specimens out of the eight examined displayed penial structures characteristic of spike-bearing species. One specimen had an inner sac with a 1-0 pattern, as in C. talarum. Another specimen had a 0-1 pattern, and an atypical specimen of $C$. pearsoni had a large pair of spikes in a 1-1 pattern (Table 1).

Ctenomys yolandae exhibits the most irregular pattern of variation. Three specimens had both spikes and spiny bulbs, following 1-1 patterns (Fig. 2). The other specimen was the only individual having a complete set of three different

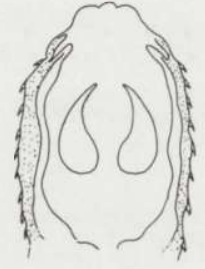
spikes
(globular)

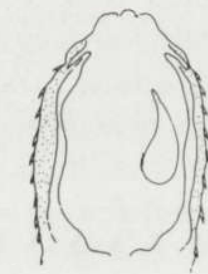

0-1 pattern

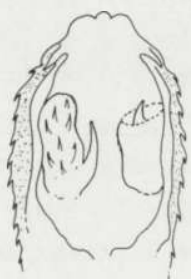

c. pearsoni

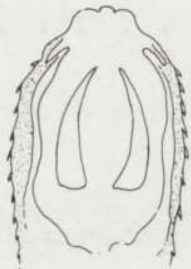

spikes (flattened)

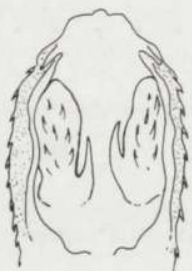

spiny bulb

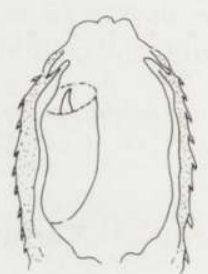

inner sac

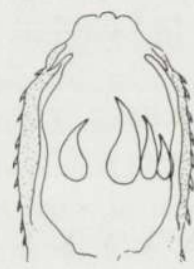

1-3 pattern

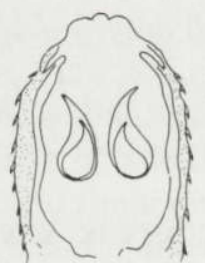

2-2 pattern

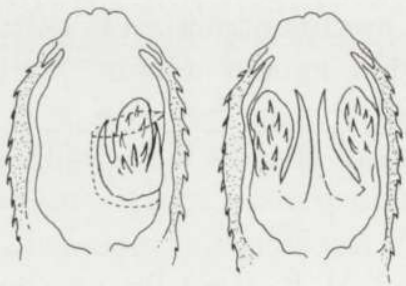

C. yolandae

Fig. 2. Schematic drawings of penial morphology features observed in the species of Ctenomys studied. Glans penis appears partially dissected in the ventral side to show the structures found inside the intromittent sac. 
penial structures. This individual had an inner sac on the left ( $0-1$ pattern), inside of which there were two large and flattened spikes (considered as $0-2$ pattern) and a spiny bulb (considered as $0-1$ pattern; Table 1, Fig. 2).

\section{Size variation of spikes and spiny bulbs}

Variability in length and width dimensions of penial structures was high, coefficient of variation being larger than $10 \%$ in most populations (Table 2). Measurement error may account for part of this high variability because of the difficulties of measuring soft structures and their small dimensions (Pankakoski et al. 1987).

In addition to an unusual pattern of spikes and the presence of an inner sac, the size and shape of the spikes also seem to differentiate $C$. talarum from the

Table 2. Sample size $(n)$, mean $(\bar{x})$ and standard deviation (SD) of maximum length and width (in $\mathrm{mm}$ ) of spikes and spiny bulbs found inside the intromittent sac in 22 populations of Ctenomys from Argentina. ${ }^{\mathrm{a}} n=9,{ }^{\mathrm{b}} n=1,{ }^{\mathrm{c}} n=3$.

\begin{tabular}{|c|c|c|c|c|c|c|c|c|c|c|}
\hline \multirow{3}{*}{ Species } & \multirow{3}{*}{ Locality } & \multirow{3}{*}{$n$} & \multicolumn{4}{|c|}{ Spike } & \multicolumn{4}{|c|}{ Spiny bulb } \\
\hline & & & \multicolumn{2}{|c|}{ Length } & \multicolumn{2}{|c|}{ Width } & \multicolumn{2}{|c|}{ Length } & \multicolumn{2}{|c|}{ Width } \\
\hline & & & $\bar{x}$ & SD & $\bar{x}$ & SD & $\bar{x}$ & SD & $\bar{x}$ & SD \\
\hline C. australis & Necochea & 6 & 4.39 & 0.45 & 1.31 & 0.18 & & & & \\
\hline \multirow{2}{*}{ C. azarae } & General Acha & 4 & 3.31 & 0.35 & 1.11 & 0.25 & & & & \\
\hline & Santa Rosa & 1 & 2.71 & - & 1.10 & - & & & & \\
\hline C. porteousi & Bonifacio & 1 & 2.52 & - & 1.06 & - & & & & \\
\hline \multirow[t]{2}{*}{ C. rionegrensis } & Ibicuy & 4 & 3.33 & 0.52 & 1.03 & 0.17 & & & & \\
\hline & Paraná & 5 & 3.07 & 0.38 & 1.16 & 0.12 & & & & \\
\hline \multirow[t]{5}{*}{ C. talarum } & Camet Norte & 10 & 1.66 & 0.25 & $0.70^{\mathrm{a}}$ & 0.11 & & & & \\
\hline & El Guanaco & 4 & 1.86 & 0.22 & 0.64 & 0.03 & & & & \\
\hline & Magdalena & 8 & 2.15 & 0.16 & 0.78 & 0.05 & & & & \\
\hline & Necochea & 11 & 1.71 & 0.45 & 0.73 & 0.09 & & & & \\
\hline & Saladillo & 9 & 2.16 & 0.27 & 0.78 & 0.12 & & & & \\
\hline \multirow[t]{2}{*}{ C. dorbignyi } & Mbaragüí & 1 & & & & & 2.58 & - & & \\
\hline & Sarandicito & 3 & & & & & 3.15 & 0.38 & 1.38 & 0.06 \\
\hline C. pearsoni & Medanos & 4 & $4.06^{\mathrm{b}}$ & - & $1.06^{\mathrm{b}}$ & - & 2.97 & 0.58 & 1.53 & 0.30 \\
\hline \multirow[t]{3}{*}{ C. perrensi } & Goya & 8 & & & & & 3.29 & 0.64 & 1.45 & 0.24 \\
\hline & Saladas & 12 & & & & & 3.03 & 0.63 & 1.35 & 0.17 \\
\hline & Yataití & 3 & & & & & 2.55 & 0.46 & 1.67 & 0.23 \\
\hline C. roigi & Costa Mansión & 6 & & & & & 2.92 & 0.45 & 1.23 & 0.14 \\
\hline C. yolandae & Las Palmas & 4 & $2.96^{\mathrm{c}}$ & 0.88 & $0.85^{\mathrm{c}}$ & 0.12 & 3.26 & 0.24 & 1.43 & 0.11 \\
\hline Ctenomys sp. & Curuzú Laurel & 2 & & & & & 2.86 & 0.16 & 1.48 & 0.10 \\
\hline Ctenomys sp. & M. F. Mantilla & 8 & & & & & 3.28 & 0.46 & 1.68 & 0.14 \\
\hline Ctenomys sp. & San Roque & 4 & & & & & 2.88 & 0.21 & 1.42 & 0.17 \\
\hline
\end{tabular}


rest of spike-bearing species. Spikes were globularly shaped and with an average length of $1.9 \mathrm{~mm}$, whereas in the rest of species spikes were flattened with an average length ranging from 2.52 to $4.39 \mathrm{~mm}$ (Table 2). Spikes of C. talarum also showed a distinctive bifurcated tip.

Average length of spiny bulbs $(3.0 \mathrm{~mm})$ was a little less than spike length (3.3 $\mathrm{mm}$, if values of $C$. talarum are excluded). Size of spiny bulbs was rather uniform among the 9 species, ranging from an average length of $3.29 \mathrm{~mm}$ in C. perrensi from Goya to $2.55 \mathrm{~mm}$ in specimens of the same species from Yataití (Table 2).

\section{Morphometric variation of the baculum}

A fully formed baculum was present in all the specimens examined even in immatures that showed no internal penial structures. The baculum in Ctenomys

Table 3. Sample size $(n)$, mean $(\bar{x})$ and standard deviation (SD) of head and body length and bacular morphometric variables (in $\mathrm{mm}$ ) studied in 22 populations of Ctenomys from Argentina.

\begin{tabular}{|c|c|c|c|c|c|c|c|c|c|c|c|c|}
\hline \multirow{2}{*}{ Species } & \multirow{2}{*}{ Locality } & \multirow{2}{*}{$n$} & \multicolumn{2}{|c|}{ Max. length } & \multicolumn{2}{|c|}{ Distal width } & \multicolumn{2}{|c|}{ Prox. width } & \multicolumn{2}{|c|}{ Height } & \multicolumn{2}{|c|}{ Body length } \\
\hline & & & $\bar{x}$ & SD & $\bar{x}$ & SD & $\bar{x}$ & SD & $\bar{x}$ & SD & $\bar{x}$ & $\mathrm{SD}$ \\
\hline C. australis & Necochea & 7 & 8.36 & 0.93 & 1.66 & 0.23 & 2.21 & 0.55 & 1.55 & 0.29 & 323.6 & 38.50 \\
\hline \multirow[t]{2}{*}{ C. azarae } & General Acha & 4 & 7.92 & 0.62 & 1.70 & 0.13 & 2.26 & 0.24 & 1.64 & 0.22 & 266.5 & 9.46 \\
\hline & Santa Ros & 1 & 7.66 & - & 2.17 & - & 1.7 & - & 1.32 & - & 254.0 & - \\
\hline C. porteousi & Bonifacio & 1 & 6.58 & - & 1.14 & - & 1.51 & - & 1.20 & - & 227.0 & - \\
\hline \multirow[t]{2}{*}{ C. rionegrensis } & Ibicuy & 5 & 7.31 & 1.28 & 1.73 & 0.18 & 1.93 & 0.32 & 1.80 & 0.57 & 290.4 & 4.21 \\
\hline & Paraná & 5 & 8.63 & 0.33 & 1.95 & 0.18 & 1.90 & 0.14 & 1.36 & 0.15 & 273.8 & 7.79 \\
\hline \multirow[t]{5}{*}{ C. talarum } & Camet Norte & 9 & 6.50 & 0.73 & 1.41 & 0.15 & 1.98 & 0.22 & 1.56 & 0.28 & 237.1 & 16.50 \\
\hline & El Guanaco & 6 & 7.10 & 1.60 & 1.41 & 0.33 & 1.94 & 0.40 & 1.50 & 0.37 & 227.8 & 8.10 \\
\hline & Magdalena & 8 & 7.99 & 0.79 & 1.45 & 0.11 & 1.92 & 0.34 & 1.88 & 0.33 & 244.5 & 6.21 \\
\hline & $\mathrm{N}$ & 1 & 16.37 & 0.76 & 1.51 & 0.19 & 1.73 & 0.33 & 1.42 & 0.18 & 225.8 & 10.66 \\
\hline & Saladillo & 8 & 6.67 & 1.15 & 1.53 & 0.34 & 1.90 & 0.28 & 1.51 & 0.23 & 241.5 & 15.14 \\
\hline \multirow[t]{2}{*}{ C. dorbignyi } & & 1 & 6.04 & - & 1.48 & - & 1.43 & - & 0.77 & - & 265.0 & \\
\hline & dicito & 6 & 8.16 & 0.41 & 1.69 & 0.09 & 2.69 & 0.36 & 1.03 & 0.13 & 297.7 & 3.08 \\
\hline C. pearsoni & Medanos & 7 & 7.27 & 0.83 & 1.63 & 0.28 & 3.14 & 0.76 & 1.92 & 0.23 & 303.4 & 22.85 \\
\hline \multirow[t]{3}{*}{ C. perrensi } & Goya & 9 & 6.54 & 1.09 & 1.34 & 0.26 & 2.24 & 0. & 1.21 & 0.30 & 290.2 & 21 \\
\hline & Saladas & 1 & 36.53 & 0.79 & 1.27 & 0.18 & 2.36 & 0.39 & 1.03 & 0.17 & 268.9 & 16.03 \\
\hline & Ya & 3 & 5.94 & 0.18 & 1.20 & 0.21 & 1.74 & 0.52 & 1.01 & 0.12 & 265.7 & 712.10 \\
\hline C. roigi & Costa Man & 6 & 5.43 & 0.96 & 1.25 & 0.07 & 2.02 & 0.25 & 0.95 & 0.11 & 279.8 & 314.69 \\
\hline C. yolandae & Las Palmas & 4 & 7.31 & 0.64 & 1.51 & 0.13 & 1.77 & 0.20 & 1.19 & 0.17 & 266.3 & $\begin{array}{l}3.21 \\
\end{array}$ \\
\hline Ctenomys sp. & & 2 & 6.80 & 1.30 & 1.64 & 0.17 & 2.42 & 0.11 & 1.13 & 0.04 & 267.5 & 54.95 \\
\hline Ctenomys sp. & M. F. Mantilla & 8 & 7.53 & 0.89 & 1.55 & 0.20 & 1.91 & 0.56 & 1.27 & 0.15 & 292.1 & 19.31 \\
\hline Ctenomys sp. & San Roque & 4 & 7.38 & 0.38 & 1.52 & 0.04 & 2.14 & 0.45 & 1.34 & 0.20 & 265.5 & 12.60 \\
\hline
\end{tabular}


is flat and positioned dorsally in the middle of the glans penis. It extends roughly $80 \%$ into the tip of the phallus (Spotorno 1979, Altuna and Lessa 1985). Variability of baculum and spike length was large, in terms of the coefficient of variation, over $10 \%$ in most of the cases, which contrasts with the low variability exhibited in length of the body (Table 3).

The baculum is paddle-shaped and its mean length ranged from $5.43 \mathrm{~mm}$ in C. roigi to $8.63 \mathrm{~mm}$ in C. rionegrensis (Table 3). Variation of the other bacular dimensions was relatively small and differences among species were minor, with the exception of $C$. pearsoni which showed a markedly wider baculum at the base (Table 3, Fig. 3). Immature individuals have a narrow rectangular base. In both populations of $C$. rionegrensis, the baculum showed a distinctive trilobulated tip, as described by Altuna and Lessa (1985). This trait was not present in any other species examined in this study. Ctenomys perrensi, C. dorbignyi, C. roigi and Ctenomys sp. from Curuzú Laurel have a more or less pronounced cleft at the base of the baculum (Fig. 3). The baculum of C. yolandae is unusual in that the base and tip have similar width and the middle portion of the shaft is narrow (Fig. 3).

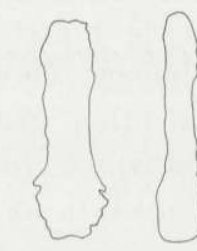

c. talarum juv.

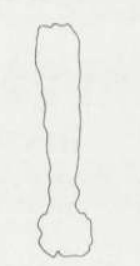

C. rionegrensis

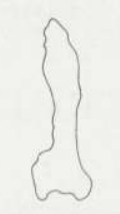

C. dorbignyi

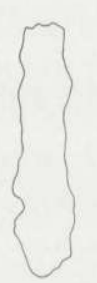

C. talarum El Guanaco

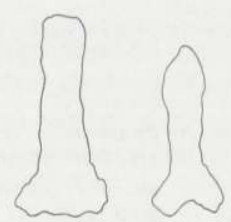

c. pearsoni

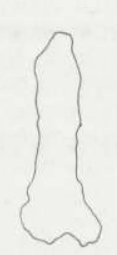

c. perrensi

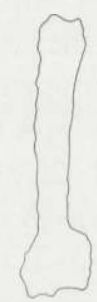

C. australis

C. yolandae

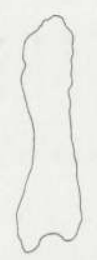

Ctenomys sp. Curuzú Laurel
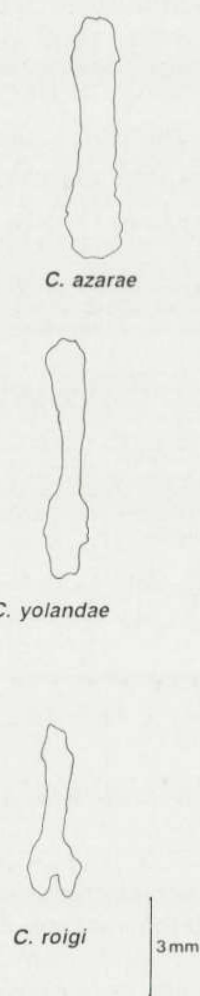

Fig. 3. Bacular morphology of 11 species of Ctenomys. 
There was some variation in bacular size among populations of C. talarum. An ANOVA of the five populations resulted in significant differences among group means in maximum length $(F=3.7, p<0.01)$ and in height at the base $(F=3.4$, $p<0.02)$. These differences reflected the contrast between Magdalena and Necochea populations, respectively the largest and smallest bacular size within C. talarum (Table 3). Differences in bacular dimensions between Magdalena and Necochea populations corresponds to overall size of individuals. Head and body length showed significant differences and conformed to the same pattern $(F=4.0$, $p<0.01$ ).

Bacular size variation was evident between specimens of Ctenomys rionegrensis from Ibicuy and those from Paraná (Table 3). Though differences were below significance level $(p<0.05)$ in the baculum measurements, head and body length showed highly significant differences $(F=17.6, p<0.003)$ suggesting that a larger sample of bacula may yield very significant differences between these two populations.

Overall similarity among species using the four bacular morphometric variables was estimated through generalized Mahalanobis' $\mathrm{D}^{2}$ distances. This analysis included 17 populations from 11 species for which sample size was at least 4 the number of variables. Coefficient of cophenetic correlation for the UPGMA phenogram was 0.72 . The phenogram produced from the matrix of $\mathrm{D}^{2}$ distances (Fig. 4) suggest two main groups of bacular morphology. One group includes C. dorbignyi, C. perrensi and C. roigi, whereas the other group includes the remaining species, (C. australis, C. azarae, C. rionegrensis, C. talarum, C. yolandae, and Ctenomys sp. from San Roque and M. F. Mantilla). In the other group,

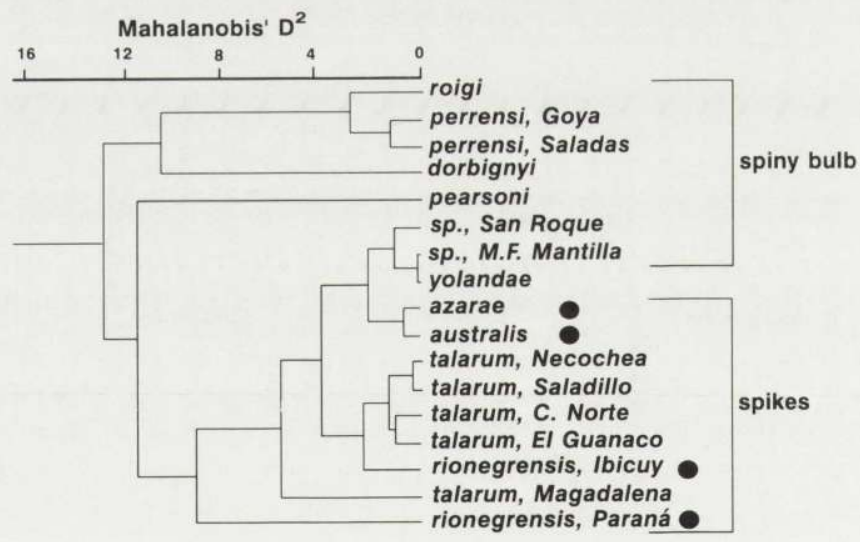

Fig. 4. UPGMA phenogram produced from a dissimilarity matrix of Mahalanobis' distance $\mathrm{D}^{2}$ between pairs of species using the 4 morphometric variables studied on the baculum. Coefficient of cophenetic correlation was 0.715 . Species are also grouped by their internal penial structures. All the species have symmetric type of sperm except those marked with a dot. Ctenomys yolandae is not included in this secondary grouping because it possesses both types of penial structures and also has a complex asymetric sperm type. 
Fig. 5. Bivariate plots of mean values $(\mathrm{mm})$ of morphometric variables from 13 species of Ctenomys used to study allometric relationships between penial structures and head and body length. Regression coefficients for the whole sample and partial $R^{2}$ for species with spikes or spiny bulbs are included. $(* p<0.05, * * * p<0.001)$.
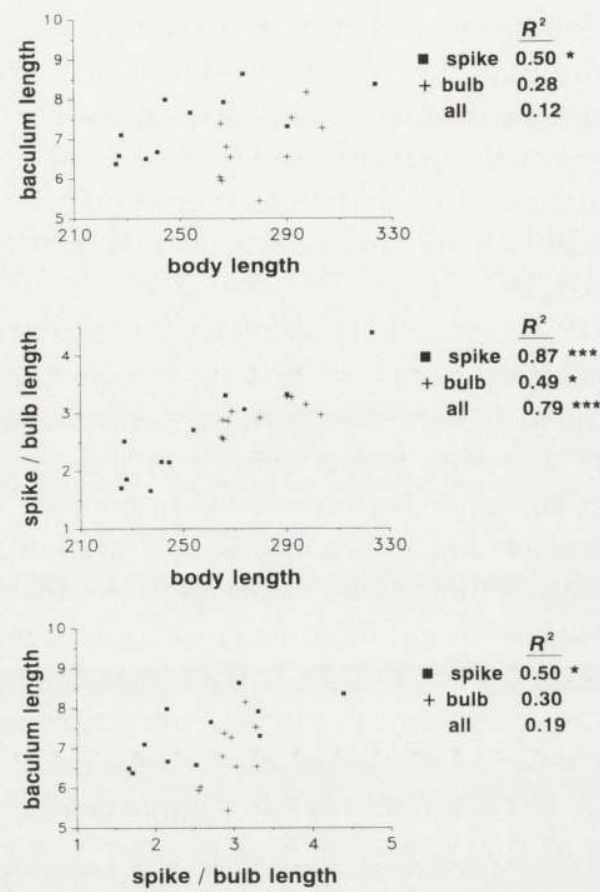

Ctenomys pearsoni is unique by having the most distinct bacular dimensions (Table 3) and shape (Fig. 3) which explains its position in the $\mathrm{D}^{2}$ phenogram (Fig. 4). Relative to the other species, $C$. pearsoni shows a well-defined wider and shorter baculum. Population variability within species seems minor in $C$. perrensi, but noticeable in C. talarum and C. rionegrensis (Fig. 4).

Allometric study of baculum length variation relative to length of the body indicates that there is no significant relationship between body and baculum lengths, nor between baculum length and length of both spikes or spiny bulbs (Fig. 5). The only statistically significant allometric relationship found was between length of the spikes and spiny bulbs and body length. Splitting the data into species with spikes or with spiny bulbs shows some differences in the allometric patterns among the two groups of species. Species with spikes show some slight correlation between bacula and spikes length and between bacula and body length, whereas $R^{2}$ coefficients in species with spiny bulb were always not significant (Fig. 5).

\section{Discussion}

Presence of penial structures inside the intromittent sac in a 1-1 pattern is characteristic of the majority of caviomorph rodents (Hooper 1961, Spotorno 1979, 
Contreras et al. 1993). It seems to be consistent for Ctenomys phalli which confirms the hypothesis of Lessa and Cook (1989). The other penial structure found inside the intromittent sac, the spiny bulb, has been previously observed only in $C$. pearsoni (Altuna and Lessa 1985). This study documents the existence of this structure in five more species as well as a 1-1 pattern in most cases (Table 1). In addition to the 1-1 pattern, this study substantiate the existence of other spike patterns (1-2, 1-3, 2-0, 2-1, 2-2, 2-3) in four species (Table 1). Contreras et al. (1993) recorded variation in patterns of spikes in some species of octodontines, ranging from 1-2 to $4-5$. Frequency of these atypical patterns in our study was much lower; only three specimens in C. talarum, and a single specimen in each of the other three spike-bearing species (Table 1). To our knowledge the inner sac of the intromittent sac adds another new penial feature occurring in Ctenomys, a feature not previously reported in any other caviomorph rodent with intromittent sacs. Functional interpretations of this secondary sac requires a detailed histological study. The inner sac may simply denote a different way of folding of the internal wall of the intromittent sac. Nevertheless, besides its functional implications, this morphological structure is a significant evolutionary character within Ctenomys, by separating C. talarum from the group of spike-bearing species.

On the basis of the main morphological structure present inside the intromittent sac, two major groups can be distinguished within our set of thirteen species from Argentina. One group of species has spikes in a 1-1 pattern that would include species distributed in the central part of Argentina (C. australis, C. azarae, C. porteousi, C. rionegrensis, and C. talarum). The remaining species are from northeastern Argentina and exhibit spiny bulbs, usually in a 1-1 pattern $(C$. dorbignyi, C. pearsoni, C. perrensi, C. roigi, Ctenomys sp. from Curuzú Laurel, M. F. Mantilla, San Roque, and C. yolandae) (Fig. 1). Association of C. pearsoni and C. yolandae with any of these two groups is problematic because they do not show an explicit pattern; some specimens even show simultaneous display of all possible structures described (Table 1). On the other hand, correlation of bacular dimensions with the presence of spikes or spiny bulbs seems low (Fig. 4), suggesting that variability of these two structures is independent from one another.

This main division into two groups agrees with data on chromosome banding patterns of heterochromatin (Reig et al. 1992) and shape of sperm (Feito and Gallardo 1982, Vitullo et al. 1988, Ortells 1990, Vitullo and Cook 1991). Within the group of spike-bearing species, C. australis, C. azarae, and C. porteousi also share a heterochromatin pattern type III (full arm type 3 C-bands present in most extensions of short arms in 50 to $75 \%$ of the chromosomes) and asymmetric type of sperm (Reig et al. 1992). In the group of species exhibiting spiny bulbs, C. dorbignyi, C. pearsoni, C. roigi and Ctenomys sp. from Curuzú Laurel and San Roque, also share a heterochromatin pattern I (C-bands fully negative in most chromosomes) and symmetric type of sperm (Reig et al. 1992). Ortells and Barrantes (1994) also recognize a similar assemblage in the species from Corrientes province using allozyme data. 
The combination of penial structures and type of sperm allows for inferences about the evolutionary history of these two groups of species, because the polarity of these two characters has been determined. Spotorno (1979) and Contreras et al. (1993) concluded that spikes in a 1-1 pattern are the probable ancestral character state because it is the most common character in caviomorphs, in Tympanoctomys (the most primitive member of the family) in some Octomys, in all species of Abrocomidae, and in some Ctenomys. Altuna and Lessa (1985), and Lessa and Cook (1989) reported the presence of spikes in 11 out of 12 species of Ctenomys, with only one having spiny bulbs (C. pearsoni). This result corroborates paired spikes as the most common form in Ctenomys and the presence of the spiny bulb as the derived condition. On the other hand, symmetric spermatozoa observed in Ctenomys are similar to those in most primitive caviomorphs and the most common sperm type in most mammalian orders. This suggests that symmetric sperm are the ancestral state for this character (Vitullo et al. 1988).

In this scenario, C. talarum would be the most plesiomorphic species within the 13 studied here, showing both spikes and symmetric sperm. All Bolivian species studied (C. boliviensis, C. conoveri, C. frater, C. lewisi, C. opimus and C. steinbachi) also show these two characters in plesiomorphic state (Lessa and Cook 1989, Reig et al. 1992) (Fig. 6). This association of C. talarum (distributed in east central Argentina) with the group of Bolivian species complicates biogeographic hypotheses about the origin of ancestral forms of Ctenomys, that propose $C$. opimus to be among the oldest species (Cook and Yates 1994). There are two derived clades, one includes seven species showing symmetric type of sperm and spiny bulb: $C$. dorbignyi, C. perrensi, C. pearsoni, C. roigi, Ctenomys sp. from Curuzú Laurel, San Roque, and M. F. Mantilla. The other derived group includes species that exhibit asymmetrical sperm type and spikes, as in four species studied here: C. australis, C. azarae, C. porteousi, C. rionegrensis; and some others: C. haigi, C. magellanicus and C. maulinus (Feito and Gallardo 1982, Lessa and Cook 1989, Contreras et al. 1993) (Fig. 6). In any case, this cladogram should be taken cautiously to explain evolution of reproductive morphology in the genus because it is based only on bacular and sperm morphology, thus representing a possible circular reasoning.

Fig. 6. Cladogram showing the evolution of two characters: type of sperm and penial structures inside the intromittent sac in some species of Ctenomys.

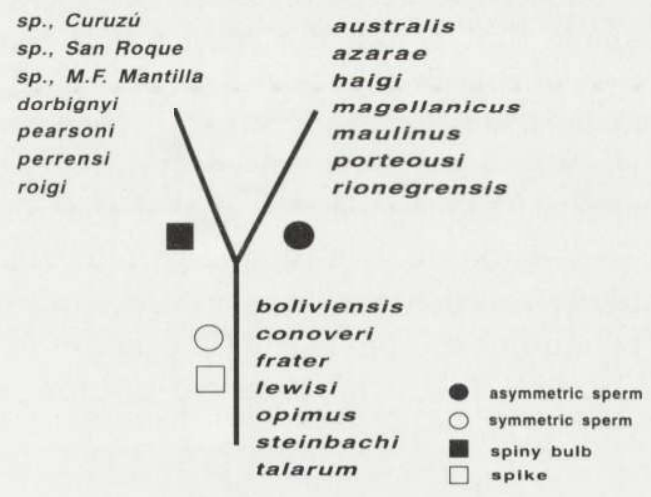


Occurrence of plesiomorphic and apomorphic characters together may agree with the hypothesis promoted by Vitullo and Cook (1991) that both sperm variants, symmetric and asymmetric, appeared at an early stage in evolution. Thus, there would be more chances of finding simultaneous occurrence of both types of sperm together with plesiomorphic and apomorphic character states of penial structures inside the intromittent sac.

In the current study, Ctenomys talarum is the only species that shows symmetric type of sperm and spikes. This species shows some atypical characteristics that separate it from the rest of the spike-bearing species, such as the more frequent occurrence of the inner sac, a shorter than average length of spikes, and globular-shaped spikes (as opposed to the flattened-shaped found in the other species). Morphometric variation of the bacular bone indicates a gradient of increased baculum size increase from south to north; cluster analysis places this species in a separate position within spike-bearing species (Fig. 4). Ctenomys talarum also has high variability in diploid and autosomal number of chromosomes $(2 \mathrm{n}=46-50, \mathrm{FN}=73-86)$ and in heterochromatin banding patterns (Reig et al. 1992). Analysis of sperm morphology indicates within population variation and an irregular symmetric spermatozoa (Vitullo et al. 1988). One possible factor that may account for high variability would be the recognition of the two subspecies within its range of distribution (Contreras and Reig 1965). However, though our samples include specimens from the two subspecies (C. t. talarum and C. t. recesus) there is no clear grouping pattern within our four populations that can be associated with these two subspecies (Tables 1,2, and 3). Similar conclusions regarding the lack of differences between these two subspecies were drawn from karyological (Ortells et al. 1984, Reig et al. 1992) and sperm morphology (Vitullo et al. 1988). Though the new data are not sufficient to synonymize these two subspecies, they do confirm the high level of intraspecific variation within C. talarum.

Ctenomys yolandae is another species that does not comply with the general pattern of the rest of species in the group of spiny bulb bearers having symmetric type of sperm. Qualitative results support the idea that this species incorporates an uncommon set of characters. Despite the small sample $(n=4)$, the adults had unique patterns of intromittent structures, and the baculum had a characteristic shape that placed the species in a separate position in the phenogram (Fig. 4). Sperm morphology also reveals some unique characteristics that separate this species within the group of asymmetric type, being the single species with complex-asymmetric sperm (Vitullo et al. 1988). The phylogenetic position of this species is ambiguous because it shows both a derived sperm type and spiny bulbs. This would imply a unique parallel change of state in one of the two traits (more likely sperm type, from symmetric to complex asymmetric). Difficulties in determining the phylogenetic position of this species were already pointed out by Ortells (1990) who observed unexpected morphological affinities of this species with C. talarum. 
Before attempting causal explanations for the penial variability patterns, the dependence or independence between overall body size variation and penial variation needs to be resolved (Patterson and Thaeler 1982). Allometric relationships among bacula, penial structures inside the intromittent sac, and head and body length, supports the conclusions of Lessa and Cook (1989) about the relative independence of the variation of phallic structures with body size. The current study documents such independence for another set of spike-bearing species, and extends this evidence to the other soft penial structure; the spiny bulb. Regression coefficients of spike size on body size resulted in low values, close to zero in the case of spiny bulbs. This lack of relationship between penial and body size variation, as well as within penial structures, is expected according to the hypothesis of independent selection for these two characters (Patterson and Thaeler 1982). This suggests that functional constraints might be responsible for this variation (Edwards 1993). Only in C. talarum was it possible to examine this relationship within taxa, showing some correlation between body and baculum variation (Table 3 ), which is likely to be age/growth related.

A major causal explanation for morphological variability in the glans penis concerns its functional significance as a potential mechanism of reproductive isolation among closely related species. Simson et al. (1993) suggest this explanation for the variability found in the bacula of Spalax ehrenbergi, another fossorial rodent also characterized by a high rate of recent speciation events. This hypothesis is applicable to Ctenomys, considering the crucial role played by the intromittent sac in reproduction. Ovulation in females is induced by cervico-vaginal stimulation (Weir 1974), probably by the spikes and spiny bulb inside the intromittent sac (Altuna et al. 1991). In addition to this stimulation, structures inside the intromittent sac are everted during erection of the penis and may help to hold the penis inside the vagina during copulation (Spotorno 1979).

To analyze the applicability of reproductive constraints as a driving force for the patterns observed, we assume that reproductive isolating mechanism should imply high degree of dissimilarity among closely related species that occur in close proximity (Patterson and Thaeler 1982). If we assume some contact between neighboring populations in our sample, geographic distribution of spikes and spiny bulb-bearing species suggest rejection of reproductive isolation mechanisms caused by penis morphology. Species showing spiny bulbs inside the intromittent sac are all distributed on the northern provinces of Corrientes and Santa Fe, whereas spike-bearing species are found in the southern provinces of Entre Ríos, Buenos Aires and La Pampa (Fig. 1). The only exception to this grouping is C. pearsoni, a spiny bulb-bearing species, occurring in Entre Ríos, close to spike-bearing species.

A functional hypothesis of penial differentiation generated to produce reproductive isolation may apply only to $C$. pearsoni, because it shows obvious dissimilarity in both bacular shape and phallic structures with neighboring species (Figs 1 and 4). The high variability of penial structures inside the intromittent sac of $C$. 
pearsoni was observed in Uruguay by Altuna and Lessa (1985). This study supports the high variability of $C$. pearsoni throughout its distribution, which might be associated with the functional hypothesis of maintaining reproductive isolation.

Rejection of reproductive isolation mechanism of the penis has special relevance in the group of six species from Corrientes because it may comply with the hypothesis of chromosomal speciation processes operating in the cladogenesis of these species (Reig et al. 1990, Ortells and Barrantes 1994, Ortells 1995). In any event, the above discussion should be taken with caution as there are many biological factors involved in reproductive isolation mechanisms that can only be resolved through comprehensive study of sympatric populations of known phylogenetic relationships. The final conclusion about the existence and possible role of reproductive isolation in this group of species is pending the appearance of a solid phylogenetic framework - reproductive isolation mechanisms would not be required if the species in contact were not closely related phylogenetically - and a thorough taxonomic appraisal of the species involved, some of which have been described only using cytogenetic data.

Acknowledgements: We are grateful to I. Rey who collected all this material with the assistance of the staff of the GIBE (Grupo de Investigación en Biología Evolutiva, Universidad de Buenos Aires). Thanks to J. A. Cook, E. P. Lessa, A. Machordom, I. Rey and A. E. Spotorno, for their careful review and helpful comments to improve previous versions of this manuscript. J. López made the drawings of penial structures. Constructive remarks from two anonymous reviewers are very much appreciated. This study was funded as a Dirección General de Investigación Científica y Tecnológica project (PB90-0144) of the Spanish Ministry of Education to O. A. Reig and M. Ponsá and a FPI research fellowship to S. R.

\section{References}

Altuna C. A., Francescoli G. and Izquierdo G. 1991. Copulatory pattern of Ctenomys pearsoni (Rodentia, Octodontidae) from balneario Solís, Uruguay. Mammalia 55: 316-318.

Altuna C. A. and Lessa E. P. 1985. Penial morphology in Uruguayan species of Ctenomys (Rodentia, Octodontidae). Journal of Mammalogy 66: 483-488.

Cook J. A. and Yates T. L. 1994. Systematic relationships of the Bolivian tuco-tucos, genus Ctenomys (Rodentia, Ctenomyidae). Journal of Mammalogy 75: 583-599.

Contreras L. C., Torres-Mura J. C., Spotorno A. E. and Catzeflis F. M. 1993. Morphological variation of the glans penis of South American Octodontid and Abrocomid rodents. Journal of Mammalogy 74: $926-935$.

Contreras L. J. and Reig O. A. 1965. Datos sobre la distribución del género Ctenomys (Rodentia, Octodontidae) en la zona costera de la Provincia de Buenos Aires comprendida entre Necochea y Bahía Blanca. Physis 25: 169-186.

Dixon W. J. 1992. BMDP statistical software manual. The University of California Press, Berkeley: 1-678.

Edwards R. 1993. Entomological and mammalogical perspectives on genital differentiation. Trends in Ecology and Evolution 8: 406-409.

Feito R. and Gallardo M. 1982. Sperm morphology of the Chilean species of Ctenomys (Octodontidae). Journal of Mammalogy 63: 658-661.

Hooper E. T. 1961. The glans penis in Proechimys and other Caviomorph rodents. Occasional Papers Museum of Zoology, University of Michigan 623: 1-18. 
Kelt D. A. and Gallardo M. 1994. A new species of tuco-tuco, genus Ctenomys (Rodentia: Ctenomydae) from Patagonian Chile. Journal of Mammalogy 75: 338-348.

Lessa E. P. and Cook J. A. 1989. Interspecific variation in penial characters in the genus Ctenomys (Rodentia: Octodontidae). Journal of Mammalogy 70: 856-860.

Lidicker W. Z. 1968. A phylogeny of New Guinea rodents genera based on phallic morphology. Journal of Mammalogy 49: 609-643.

Nevo E. 1982. Speciation in subterranean mammals. [In: Mechanisms of speciation. C. Barigozzi, ed]. Alan R. Liss Inc., New York: 191-218.

Ortells M. O. 1990. Biología evolutiva en el género Ctenomys (Rodentia, Octodontidae). Ph D thesis, Universidad de Buenos Aires, Buenos Aires: 1-220.

Ortells M. O. 1995. Phylogenetic analysis of G-banded karyotypes among the South American subterranean rodents of the genus Ctenomys (Caviomorpha: Octodontidae) with special reference to chromosomal evolution and speciation. Biological Journal of the Linnean Society 54: 43-70.

Ortells M. O. and Barrantes G. E. 1994. A study of genetic distances and variability in several species of the genus Ctenomys (Rodentia, Octodontidae) with special reference to a probable causal role of chromosomes in speciation. Biological Journal of the Linnean Society 53: 189-208.

Ortells M. O., Vitulio A., Merani M. S. and Reig O. A. 1984. Identidad cromosómica entre dos razas geográficas de tuco-tucos (Ctenomys talarum). Revista del Museo Argentino de Ciencias Naturales Bernardino Rivadavia, Zoología 13: 479-484.

Pankakoski E., Vaisanen R. A. and Nurmi K. 1987. Variability of muskrat skulls: measurement error, environmental modification and size allometry. Systematic Zoology 36: 35-51.

Patterson B. D. and Thaeler C. S. 1982. The mammalian baculum: hypotheses on the nature of bacular variability. Journal of Mammalogy 63: 1-15.

Pocock R. I. 1922. On the external characters of some hystricomorph rodents. Proceedings of the Zoological Society of London 25: 365-427.

Reig O. A., Busch M. O., Ortells M. O. and Contreras J. R. 1990. An overview of evolution, systematics, population biology and speciation in Ctenomys. [In: Biology of subterranean mammals at the organismal and molecular levels. E. Nevo and O. A. Reig, eds.]. Alan R. Liss Inc. New York: $71-96$.

Reig O. A., Massarini A. I., Ortells M. O., Barros M. A., Tiranti S. I. and Dyzenchauz F. J. 1992. New karyotypes and C-banding patterns of the subterranean rodents of the genus Ctenomys (Caviomorpha, Octodontidae) from Argentina. Mammalia 56: 604-623.

Rohlf F. J. 1992. NTSYS-pc. Numerical Taxonomy and Multivariate Analysis System. Exter Software. New York.

Simson S., Lavie B. and Nevo E. T. 1993. Penial differentiation in speciation of subterranean mole rats Spalax ehrenbergi in Israel. Journal of Zoology, London 229: 493-503.

Spotorno A. E. 1979. Contrastación de la macrosistemática de roedores caviomorfos por análisis de la morfología reproductiva masculina. Archivos de Biología Médica Experimental 12: 97-106.

Vitullo A. D. and Cook J. A. 1991. The role of sperm morphology in the evolution of Tuco-Tucos, Ctenomys (Rodentia, Ctenomidae): confirmation of results from Bolivian species. Zeitschrift für Säugetierkunde 56: 359-364.

Vitullo A. D., Roldan E. R. and Merani M. S. 1988. On the morphology of spermatozoa of tuco-tucos, Ctenomys (Rodentia, Ctenomidae): New data and its implications for the evolution of the genus Journal of Zoology, London 215: 675-683.

Weir B. J. 1974. Reproductive characteristics of Hystricomorph rodents. Symposia of the Zoological Society of London 34: 265-301.

Williams S. L. 1982. Phalli of recent genera and species of the family Geomydae (Mammalia: Rodentia). Bulletin of Carnegie Museum of Natural History 20: 1-62.

Woods C. A. 1993. Suborder Hystricognathi. [In: Mammal species of the world. D. E. Wilson and D. M. Reeder, eds]. Smithsonian Institution Press, Washington: 1-1206.

Received 24 October 1995, accepted 17 May 1996. 